\title{
Guiding Diabetic Therapy for Children and Adolescents with Type I Diabetes
} Sheryl Zang EdD, FNP, CNS-BC, Veronica P. Arikian PhD, RN

Associate Professor, College of Nursing, SUNY Downstate Medical Center, Brooklyn, NY, United States.

Article Details
Article Type: Research Article
Received date: $09^{\text {th }}$ October, 2019
Accepted date: $21^{\text {st }}$ November, 2019
Published date: $23^{\text {rd }}$ November, 2019
"Corresponding Author: Sheryl Zang, Associate Professor, College of Nursing, SUNY Downstate Medical Center, Brook-
lyn, NY, United States. E-mail: sheryl.zang@,downstate.edu
Citation: Zang S, Arikian VP (2019) Guiding Diabetic Therapy for Children and Adolescents with Type I Diabetes. J Comp
Nurs Res Care 4: 153 . doi: https://doi.org/10.33790/jcnrc1100153.
Copyright: O2019, This is an open-access article distributed under the terms of the Creative Commons Attribution License
4.0, which permits unrestricted use, distribution, and reproduction in any medium, provided the original author and source are
credited.

\section{Abstract}

Studies indicate children and adolescents with Type 1 diabetes need treatment with multiple daily insulin injections (MDI) or subcutaneous insulin infusion (CSII) for glycemic control. This research study explored the efficacy of MDI's compared to CSII therapy in children and adolescents with Type I diabetes in an urban setting by examining their HgbA1C outcomes. Retrospective chart review examined 58 records of children and adolescents (ages 0-21) in two outpatient settings who transitioned from MDI's to CSII. HgbA1c values were recorded during MDI use over one year and during the initial year of CSII use and the means were compared. The difference in mean $\mathrm{HbAlc}$ values during MDI and CSII therapies were tested using paired t-tests. HgbAlc values differed between age groups under and over 13. Reduction in mean HbA1c of 0.79 $(\mathrm{p}=0.02)$ in the older group was statistically significant. The change in the younger group of $-0.09(\mathrm{p}=0.75)$ was not significant. Results suggest that children over 13 have improved glycemic outcomes using pump therapy. Nurses can build a long-term relationship with the patient and family, teaching self-management and offering choices of insulin administration as this study revealed that there was no difference in how they received insulin.

\section{Purpose/Aims}

According to the Juvenile Diabetes Research Foundation (JDRF), as many as 1.25 million Americans are living with Type I Diabetes (T1D), including about 200,000 children and adolescents who are less than 20 years old. Between 2001 and 2009, there was a 21 percent increase in the prevalence of T1D in people under age 20. Less than one-third of people with T1D in the U.S. are consistently achieving target blood-glucose control levels. Recommendations from the landmark multisite studies, Diabetes Control and Complication Trial and the Epidemiology of Diabetes Interventions and Complications (EDIC) (1994-present), [1], indicate that adolescents with Type 1 diabetes should be treated with intensive therapy involving multiple daily insulin injections or insulin pump therapy to obtain better glycemic control and prevent later complications. Although studies have shown that insulin pump use has risen among children and adolescents with improved glycemic results, it has been noted that, on evaluation of HgbA1c, pump use by children and adolescents in the two clinical sites in Brooklyn did not necessarily lower blood glucose levels [2]. In fact, according to the clinic records, some $\mathrm{HgbA1}$ c results remained elevated. There has been no evaluation to determine which treatment regimen more favorably affects HgbAlc in this urban, low socio-economic population.
For example, several children and adolescents in the two institutions were switched from multiple daily injections of insulin (MDI's) to continuous subcutaneous insulin pump therapy (CSII), as parents and children/adolescents chose to do so with medical approval. The pumps used were the Medtronic Paradigm, the Animas Ping and Omnipod. Children and adolescents were not using continuous glucose monitors at the time of this study (2017). Standard pumps were used. Technological advances in the field of diabetes have provided new tools, this study did not reflect the use of sensor/ augmented insulin pump therapy.

Recently, recommended A1c targets have been adjusted to less than $7.5 \%$ owing to improved tools for diabetes management and a greater understanding and recognition of the adverse effects of chronic hyperglycemia on the developing brain, and a lower goal is reasonable if it can be achieved without excessive hypoglycemia [3].

The standard of care for Type 1 diabetes is to use either therapy modality. However, there is a gap in the literature regarding the relationship between method of insulin delivery, age, and glycemic outcomes [1].

According to Yeh, et. al. [4], insulin delivery technologies are widely used, may be expensive, and aggressively marketed, however, their effectiveness and populations most likely to benefit are not clear. What is required is objective information to make appropriate decisions about ideal modalities for specific populations. Since many children and adolescents in our population in Brooklyn, NY were started on MDI's and not on pump therapy when newly diagnosed with Type 1 diabetes, the authors chose to compare glycemic outcomes as a measure of successful control. To assess average glucose results over the past three months, A1c levels should be monitored for all individuals with Type 1 diabetes. Although it is still under $10 \%$, recent reports from a U.S. diabetes registry estimate that CGM use in pediatric patients consistently increased between 20102014 and sharply rose in 2014-2016. The largest increase was in very young children (ages 2-5 years), in whom CGM use was approaching $40 \%$ [5]. Continuous glucose monitoring (CGM) has been on the rise, but the population studied was doing finger sticks when the data was collected. HgbAlc values were collected from the medical records of children/adolescents who started on MDI's for at least one year, and then switched to pump therapy for at least one year. Many factors contributing to the successful management of Type I Diabetes are parental support, patient/family education, health literacy, and understanding of diet and correct insulin doses. These factors influence the rate of development of diabetes complications [6-9]. 
A modality that works for the patient and the family should address as many factors as possible. This study planned to offer evidence for the clinical nurse specialist, parent and child/adolescent about which type of insulin administration provides better glycemic control.

The research question is: What is the efficacy of multiple daily injections (MDI's) compared to continuous subcutaneous insulin pump therapy in the treatment of children and adolescents with Type I diabetes in an urban setting?

The hypothesis is: Continuous subcutaneous insulin pump therapy improves glycemic control in children and adolescents (ages 0-21) who were originally receiving MDI's for at least one year, and then transitioned to continuous subcutaneous insulin injection and maintained this therapy for at least one year.

Several studies compare the benefits of multiple daily injections and continuous subcutaneous pump therapy and support the safety and long term efficacy of insulin pump therapy [2,4,10-12]. For example, Jakisch et. al. [11] found in a 3-year follow up study that patients using either MDI or CSII achieve the same level of glycemic control, and in fact, although CSII was superior during the first year, the difference did not persist. Other studies suggest that adequate glycemic control in Type I diabetes requires significant patient education and adaptation of therapy choice to the individual patient's way of life [13]. Additional considerations that the literature revealed included the important roles of parental stress, self-care, psychosocial distress, depression, quality of life and socioeconomic status on successful maintenance of HgbAlc in children and adolescents $[2,6]$. The literature review suggests that successful glycemic control is dependent on a multifactorial model, taking not only age, socioeconomic status, and parental support into consideration, but also assiduous maintenance of routine in the administration of whatever therapy modality suits the developmental and lifestyle needs of both the child/adolescent and parent/family. Children learn to self-manage their diabetes gradually during childhood. The major task for diabetic adolescents is separating from parents and being able to independently manage diabetes and the normalizing task is "taking on the burden of care." Tasks identified that are part of care include transitioning from parental care, independently monitoring blood sugar, taking over administration of insulin, and managing diet and activity independently. They also need to know what to do when feeling symptoms of hyperglycemia or hypoglycemia and when to get help from others. Diabetes self-management (DSM) is very complex with over 600 tasks needed to manage diabetes effectively [14] and include not only the physical tasks needed for glycemic control, but emotional adjustment to having a chronic illness. For adolescents to transition to self-management, they have to juggle the multiple responsibilities of home, school, work and social relationships. Diabetic self-management also includes needed skills in decision-making and problem solving, for example, planning and calculating insulin requirements based on carbohydrate counting and sick day management.

The Self-Care Deficit Theory of Dr. Dorothea Orem was the guiding conceptual framework for this study. Dr. Orem's theory has developed over the last 40 years, and four cognitive operations have been identified as key to applying the theory to practice. These are: diagnostic, prescriptive, regulatory and control. These operations are designed to be collaborative so that the patient has input into care decision-making. Diagnostic and prescriptive actions set the stage for how the patient, caregivers and nurse will address the selfcare needs and potential needs, regulatory action takes place during the operational phase, and control implies evaluation of the efforts made [15]. The theory states that people should be self-reliant and responsible for their own care and others in their family needing care, http://currentnursing.com/nursing_theory/self_care_deficit_theory. $\mathrm{html}$, and self-care is vital as older children and adolescents take on more independent care of their diabetes and learn the steps successfully to keep their glycemic levels under control. Such self-care needs to take place in an incremental and structured way to provide guidance for parents and their children. Transition is difficult for both parents and the child/adolescent so well-thought out strategies are needed to assist them to self-management. Such conditions occur when children/adolescents are able to transition from their parents, when their parents are willing to let go, when they have the skills to take over, are older, and emotionally ready to take on management of care [16]. (the selfcare theory should be explained in more detail and should be clearly linked to the research question).

\section{Design}

The design of this study is retrospective, comparative and descriptive, using the medical records of 58 children and adolescents from two outpatient Diabetes Clinic, one located in a city hospital and one located in a state hospital in East Flatbush, Brooklyn, New York. The team consisted of three pediatricians, two doctorally prepared nurses, a nutritionist, and a research assistant. The study was submitted to and approved by the Institutional Review Board of SUNY Downstate Medical Center. The population was drawn from the two clinics using specific inclusion criteria: age (under 22 years), length of time on MDI's (minimum one year), and length of time on CSII (minimum one year). Demographic information collected included date of birth, gender, exact age at diagnosis, and age at transition from MDI's to CSII. Race and ethnicity of the samples reflected the Caribbean and African populations of the neighborhood. Identifying information was not collected or linked with the coded participant.

\section{Methods}

Methodology included data collection for each child/adolescent selected for the study of at least two, but no more than four, HgbAlc values taken and recorded over the course of the year during which the child/adolescent was using MDI's as the insulin therapy administration. In addition, at least two, but no more than four, HgbAlc values were taken and recorded over the course of the subsequent year during which the child/adolescent was using CSII as the insulin therapy administration.

\section{Results}

There were 58 patients in the study. A paired t-test was selected to determine whether there was a statistical difference in means between glycemic outcomes for MDI use and for CSII use. An alpha of .05 and a confidence interval of $95 \%$ was used to compare the final $\mathrm{HbAlc}$ measurements of MDI and CSII. The study was limited to a small sample size, and power analysis was not conducted based on the recommendations of the College's statistician.

The sample consisted of 54 children/adolescents of AfricanAmerican descent and 4 children of Yemeni descent. It was drawn from the medical records of two Endocrinology clinics in East Flatbush, Brooklyn, NY. Ages of the sample ranged from 8 months to 21 years.

The overall effect [for the entire sample], was not significant. The means (SD) were 10.5 (2.0) and 10.2 (2.0) for the MDI and CSII periods, respectively. The estimated difference was 0.29 (95\% CI -0.16 to $0.73, p=0.20$ ). (table 1 or table 2 ? For all results table number should be cited.).

The change in HbAlc did not differ between genders $(p=0.28)$. Mean (SD) [for the difference between the average measurements in MDI and CSII periods] were 0.09 (1.71) in females and 0.57 (1.67) in males (Table 1).

Additionally, the age group of $0-21$ was divided into two, 0-12 and 13-21 at the age of transition from MDI and CSII. The rationale for dividing the age groups, based on Orem's Self-Care model, suggests that adolescents would likely be in more control of their diabetic self-management, whereas younger children would have their care managed by parents or caregivers. HgbAlc values differed between age groups under and over 13. Results showed that the mean 


\begin{tabular}{|l|l|l|}
\hline & Change in Mean HgbA1c Value & $\mathrm{p}$ Value \\
\hline Older Group Over 13 & 0.79 & $0.02 *$ \\
\hline Younger Group Under 13 & -0.09 & 0.75 \\
\hline *Statistically significant & $\begin{array}{c}\text { Oalues for Children Under 13 and Adolescents } \\
\text { over 13 }\end{array}$ \\
\hline
\end{tabular}

[SD] for HbA1c measurements were 10.09 [2.18] and 10.29 [2.37] of MDI and CSII, respectively. Reduction in mean HbA1c of 0.79 $(p=0.02)$ in the older group was statistically significant. The change in the younger group of $-0.09(\mathrm{p}=0.75)$ was not significant. The results offer information suggesting that children over 13 have improved glycemic outcomes using pump therapy.

The final HgbA1c's were compared hypothesizing that it would be improved since the child/adolescent and families would have a full year to incorporate diabetic management into their lifestyles. The mean difference between the last observations for MDI and CSII was estimated to be -0.20 [95\% CI -0.72 to $0.32, p=0.44]$ and was not significant. Table 2 below provides summary for the final observations for MDI and CSII.

\begin{tabular}{|l|l|l|l|l|l|}
\hline Variable & $\mathrm{N}$ & Mean & Std Dev & Minimum & Maximum \\
\hline Last Obs MDI & 58 & 10.09 & 2.18 & 5.90 & 16.60 \\
\hline Last Obs CSII & 58 & 10.29 & 2.37 & 6.30 & 16.80 \\
\hline \multicolumn{7}{|l}{ Table. 2 - Final Observations for MDI and CSII } \\
\hline
\end{tabular}

This study is limited by several factors. It did not reveal if the diagnosis of diabetes was managed on an outpatient basis or the child/adolescent was hospitalized. It did not reflect the amount of ongoing education, especially after the first HgbAlc was recorded. The study also did not reflect how much pump teaching or support the patient and family received. Ongoing diabetic education at each visit must be reinforced and needs to be geared to the child's age and developmental level. After the first HgbAlc is recorded, diabetic management has to be evaluated and intense monitoring of blood glucose levels, documentation of meal monitoring and insulin administration based on blood glucose and carbohydrate counting must be a part of the follow up visit. Pump understanding and comfort level with problem solving has to be reviewed at every visit. It is recommended that the child/adolescent/family be evaluated by a diabetic team consisting of diabetic nurse educators, pediatric endocrinologists, dieticians and mental health professionals.

The two sites studied had similar socioeconomic populations and demographics. This was a retrospective chart review and information in the records to address health literacy, English as a second language or consistent patient education and whether these played a significant role in the HgbAlc outcomes was not available. It was not possible to distinguish the barriers to adherence, such as not testing blood sugar or administering correct doses of insulin and complying with the recommended diet and access to appropriate food. In addition, information regarding hospitalizations, ER visits, or episodes of hypoglycemia was not available. Other confounding variables that may influence HgbAlc and were not included are hormonal influences and menstruation, growth spurts and weight gain, exercise and sports program participation, illnesses and underlying infection. Additionally, other concerns include adolescent rebellion and risk factors. The demands of self-management of Type 1 diabetes in adolescence include both the physical demands and the emotional and social demands of adjustment. Several studies have shown that psychosocial factors, such as stressors and coping styles during the period of adolescence are often associated with neglect of selfmonitoring, dietary recommendations, and insulin injections [17]. Many factors contributing to the successful management of Type I diabetes are parental support, patient/family education, health literacy, and understanding of diet and correct insulin doses. These factors influence the rate of development of diabetes complications [6].

\section{Conclusions}

Thorough patient education and complying with medical recommendations is certainly needed, but choice of insulin administration and ways of achieving glycemic control need to fit the child/ adolescent and family's lifestyle and individual determination of therapeutic goals. The results of this study revealed that there was no difference in how the child and adolescent received insulin. Meta-analyses of randomized controlled trials have shown modest differences between insulin pump therapy and injection regimens for improving glycemic control and reducing hypoglycemia. Results in children have thus far been equivocal [18-24].

This is very important for providers in practice, especially nurses and advanced practice nurses, as the goal is to have the children, adolescents and families use a form of insulin they are most comfortable with and that the child and adolescent can manage their chronic illness and be as independent in self-care as they are able. Nurses must take a good medical, family and social history and discern the current treatment plan but it is also vital to know the child, adolescent and family's level of confidence in their ability to manage diabetes and their current challenge with diabetes. The nurse should ask this question at every visit because the challenges change frequently. A family can be coping well and then hit a rough patch. During childhood, diabetes is never stable, and during adolescence many teens don't want to deal with their condition. This can cause some very difficult family dynamics [16]. The nurse has to give families realistic expectations about the uniquely dynamic nature of diabetes in the context of child development.

One of the most important aspects of nursing practice is to help the family decide which type of insulin administration will work for them. If a child or teen has been using MDI's and decides to change to a CSII, the nurse is in a position to initiate pump therapy. The nurse can discuss the pros and cons of insulin pump therapy, including choice of pumps and infusion sets. The nurse can demonstrate pump programming and function applications, administration of basal and bolus doses, insulin supplementation for high blood glucose levels, the protocol for clogged infusion sets, pump alarms and discuss when to seek medical help. The nurse needs to review blood glucose levels and insulin rates, troubleshoot pump questions, as well as review blood glucose levels and suggest basal and bolus rate adjustments as needed. A change to insulin pump therapy is a major therapeutic and lifestyle adjustment for people with diabetes. The nurse's careful attention to the emotional, physiological, educational, and psychological aspects of insulin pump therapy should ease the transition. The nurse can also help children, adolescents and families change from the pump to MDI's, providing education and support for successful diabetic management. 
There were many variables that were not studied. In order to achieve optimal glycemic control, it is interesting to compare if a child/adolescent were hospitalized or managed on an outpatient basis and if the type of teaching received had an impact on their diabetic management and adherence. It is interesting to assess if a team approach or an individual provider has an effect on glycemic control. It is vital to compare how much pump training the child/family received and the effect on glycemic control. Since this diagnosis is new to families, support groups may be a way to provide continued support. Since our sample was derived from an urban, low socioeconomic clinic population it was recommended that this study be replicated in a different socioeconomic area or with a population that has different ethnic and cultural influences.

\section{References}

1. Danne T, Phillip M, Buckingham BA, Jarosz-Chobot P, Saboo B et al. (2018) ISPAD Clinical Practice Consensus Guidelines 2018: Insulin treatment in children and adolescents with diabetes. Pediat Diabetes 19: 115-135.

2. Borsboom NR, Nuboerr, Zoethout JA, Koot HM, Bruining $\mathrm{J}$ et al. (2008) Effects of insulin pump vs. injection treatment on quality of life and impact of disease in children with type 1 diabetes mellitus in a randomized, prospective comparison. Pediat Diabetes 9: 291-296.

3. Chiang JL, Kirkman MS, Laffel LMB, Peters AL (2014) Type 1 Diabetes Sourcebook Authors. Type 1 diabetes through the life span: a position statement of the American Diabetes Association, Diabetes Care 37: 2034-2054.

4. Yeh HC, Brown TT, Maruther N, Ranasinghe P, Berger Z (2012) Comparative effectiveness and safety of methods of insulin delivery and glucose monitoring for diabetes mellitus: A systematic review and meta-analysis. Annals of Internal Med 157: 336-347.

5. Miller KM, Foster NC, Beck RW, Bergenstal RM, DuBose SN et al. (2015) Current state of type 1 diabetes treatment in the US: Updated data from the T1D Exchange Clinic Registry. Diabetes Care 38: 968-70.

6. McMahon SK, Airey FL, Marangou DA, McElwee KJ, Carne CL et al. (2004) Insulin pump therapy in children and adolescents: improvements in key parameters of diabetes management including quality of life. Diabetic Medicine 22: 92-96.

7. Nambam B, DuBose SN, Nathan BM, Beck RW, Maahs DM et al. (2018) T1D Exchange Clinic Registry. PO34.

8. Wangnoo S (2015) Initiating insulin therapy in children and adolescents with type 1 diabetes mellitus. Indian J Endocrinol Metabolism 19: S68-S70.

9. Weinzimer SA, Ahern JH, Doyle EA, Vincent MR, Dzur J et al. (2004) Persistence of benefits of continuous subcutaneous insulin infusion in very young children with type 1 diabetes: A followup report. Pediat 114: 1601-1605.

10. Fendler W, Baranowska AI, Mianowska B, Szadkowska A, Mlynarski W, et al. (2012) Three-year comparison of subcutaneous insulin pump treatment with multi-daily injections on HbA1c, its variability and hospital burden of children with type 1 diabetes. Acta Diabetologica 49: 363-370.

11. Jakisch BI, Wagner VM, Heidtmann B, Lepler R, Holterhurst PM, et al. (2007) Comparison of continuous subcutaneous insulin infusion (CSII) and multiple daily injection (MDI) in paediatric Type I diabetes: A multicenter matched-pair cohort analysis over 3 years. Diabetic Med 10: 80-85.

12. Ahern JAH, Boland EA, Doane R, Ahern JJ, Rose P et al. (2002) Insulin pump therapy in pediatrics: a therapeutic alternative to safely lower HbA1c levels across all age groups. Pediatr Diabetes 3: 10-15.
13. Krzymien J, Rachuta M, Kozlowska I, Ladyzynski P, Foltynski $P$ et al. (2015). Treatment of patients with type 1 diabetesInsulin pumps or multiple injections? Biocybernetics and Biomedical Engineering.

14. Coffen RD (2009) The 600-step program for Type 1 diabetes self-management in youth: The magnitude of the selfmanagement task. Postgraduate Med 121: 119-139.

15. Berbiglia V (2002) Orem's Self-Care Theory in Practice, Chapter 12. In Alligood, M.R. and Tomey, A.M. (2002). Nursing Theory, Utilization and Application. St. Louis, MO: Mosby 239-266.

16. Babler E, Strickland J (2015) Moving the journey towards independence: Adolescents transitioning into successful diabetes self-management. J Pediat Nurs 30: 648-660.

17. Grey M, Boland EA, Davidson M, Yu C, Tamborlane W et al. (1999) Coping skills training for youths with diabetes on intensive therapy. Applied Nurs Res 12: 3-12.

18. Chiang J, Maahs DM, Garvey KC, Hood KK, Laffel LM et al. (2018) Diabetes Care 41: 1-19.

19. Nabhan ZM, Kreher NC, Greene DM, Eugster EA, Kronenberger, W, et al. (2009) A randomized prospective study of insulin pump vs. insulin injection therapy in very young children with type 1 diabetes: 12-month glycemic, BMI and neurocognitive outcomes. Pediat Diabetes 10: 202-208.

20. Wu YP, Montserrat MG, Roberts MD, Mitchell AC (2010) Is insulin pump therapy better than injection for adolescents with diabetes? Diabetes Res Clini Pract 89: 121-125.

21. Weintraub N, Benzaquen H, Galatzer A, Shalitin S, Lazar L et al. (2003) Comparison of continuous subcutaneous insulin infusion and multiple daily injection regimens in children with type 1 diabetes: a randomized open crossover trial. Pediat 112: 559-564.

22. Alligood MR, Tomey AM (2002) Nursing Theory, Utilization and Application. St. Louis, MO: Mosby.

23. Doyle EA, Weinzimer SA, Steffen AT, Ahern JA, Vincent M et al. (2004) A randomized, prospective trial comparing the efficacy of continuous subcutaneous insulin infusion with multiple daily injections using insulin glargine. Diabetes Care 27: 1554-1558.

24. American Diabetes Association (2016) Children and adolescents, type 1 diabetes. Sec. 11. In Standards of Medical Care in Diabetes-2016. Diabetes Care 1: S86-S93. 